\title{
Using illness narratives to identify community perceptions of trauma and cancer risks in Kuwait
}

\author{
Charles W Cange \\ 1 Department of Health Sciences, Lehman College, The City University of New York (CUTY), New York, New York, USA \\ Keywords: kuwait, cancer, trauma, illness narratives, global health \\ https://doi.org/10.29392/joghr.3.e2019005
}

Journal of Global Health Reports

Vol. 3, 2019

\begin{abstract}
Background
I set out to investigate whether the Kuwaiti environmental health community believed there were psychosocial and chemical factors that influenced the advent of breast cancer in post-Gulf War Kuwait.
\end{abstract}

\begin{abstract}
Methods
In semi-structured interviews with the Kuwaiti environmental health community, I documented participants' explanations of the community's diseases. I spoke with 26 community members based on a purposive sampling scheme and analyzed the transcriptions by identifying their illness narratives. Three themes emerged from the data. First, as outlined in the section "Collective Trauma: Violence Embodied," the majority of Kuwaitis were affected by an intense amount of trauma. Indeed, PTSD rates have stayed the same in Kuwait since 1991 ( 20\%).
\end{abstract}

\section{Results}

In the theme "A Toxic Legacy: War and Chemical Exposures," a common refrain I heard was "Cancer's running like a flu now; every family has a case of cancer.” Much higher rates of cancer were reported in the post-conflict period. Third, in "Defining Invisible Risks," individuals expressed disdain for the Ministry of Health's approach to post-conflict health; they reported that it should actively research links between disease and chemical exposures.

\section{Conclusions}

Kuwaitis found physical health concerns were deemed more legitimate than concerns about mental health. My informants described the administration's lack of transparency or trustworthiness in handling their concerns. They called for a formal investigation into the war's toxic effects on future generations of Kuwaitis' health and well-being.

In this article, I describe how I employed my qualitative methods in Kuwait, and I report the main results of this investigation. My project sought out Kuwaitis to discuss their unique and indigenous viewpoint on environmental and health issues related to the Gulf War. Herein I develop an ethnographic, public health-based approach by meeting with and interviewing key informants in the Kuwaiti medical and environmental community sectors (ie, Key Informant Interviews).

The methods in this article are concise and provide sufficient depth to investigate the issues at stake. First, questions around war-related health issues incite data triangulation. This triangulation is indeed best accomplished by using qualitative methods for two reasons. ${ }^{1,2}$ Anecdotal evidence collected through interviews and participant observation allow the researcher to unearth the community's impressions and perceptions. Secondly, qualitative methods tend to offer more explanation for the wider context of a problem such as the Gulf War, and thereby condition and encourage the investigator to include diverse underlying factors that may be sidelined or minimized in a purely quantitative analysis.

Working in a foreign country and in foreign conditions requires the researcher to make constant adjustments to his or her research protocol. As a community outsider, I relied heavily on ethnography and participant observation, common anthropologic tools of inquiry. In this article, I identify the best approaches to answer my research questions, and, indeed, I attempt to explain the myriad tools at one's disposal in this type of project. This approach analyzed community health concerns in a qualitative way. As such I was able to conduct many interviews within the environmental and health communities on individuals' perceptions and concerns regarding cancer and particularly breast cancer risk in Kuwait after the Gulf War. In this article, I am posing the following question: does the Kuwaiti environ- 
mental health community believe that there are psychosocial (eg, trauma, alienation) and chemical factors that influenced and/or exacerbated the rates of breast cancer in post-war Kuwait? This question is posed in a context where the State controls the public dissemination of information regarding cancer risks.

I also explain my recruitment methods detailing the population, who the participants are, how they were selected, the linguistic rapport between participant and researcher, informed consent, and the questions on the interview guide.

\section{METHODS}

\section{MUWAHAJA APPROACH}

Abu-Lughod implores researchers to consider the relationship between individual encounters and the larger statements that researchers weave when drafting generalizations from their subjects "showing their actual circumstances and detailed histories". ${ }^{3}$ One can imagine piecing together these histories into a collective memory. Post-conflict, participatory principles ${ }^{4,5}$ encourage the researcher to empower their subjects by adopting a more passive role, acutely listening and, when useful, providing feedback to the respondent. This approach includes the ethnographic research I conducted using informal interviews with doctors, patients and family members.

When I first went to Kuwait in 2007, my goal was to meet people and listen with few preconceptions to their disease narratives. Many public health experts believe post-conflict public health impacts originate from small increases in individual risks distributed across populations. ${ }^{6}$ The inherent interconnectedness between epidemiology and anthropology became evident through my research on the Kuwaiti population during this project. ${ }^{7,8}$ I was continually carrying out my research plan in a culturally sensitive way while maintaining a rigorous qualitative methodology. To this extent, my project strived to reach out to civilians who traditionally might not be identified as victims of armed conflict. Indeed, most war-focused public health research does not focus on civilians. "Reaching out" means communicating with patients on their level and on their terms- for example, avoiding questions filled with medical jargon. ${ }^{3}$ This concept will be further delineated while discussing explanatory models in the following section.

My fieldwork data were collected in this study via participant observation and semi-structured interviews with participants from the Kuwait environmental health community and a few breast cancer patients in Kuwaiti clinics.

In the semi-structured patient interviews (part of a larger Quality of Life survey of chronic disease patients in Kuwait), I relied on participants' explanations of the community's diseases. As Kleinman defined explanatory models, participants often bring their own interpretation of the illness' origin. ${ }^{9}$ I encouraged the study participants to be actively engaged in the project from its onset. Thus, two approaches informed my interactive approach during unstructured interviews: disease narratives and explanatory models. ${ }^{10-12}$ These interviews and my transcribed field notes shed light on participants' health and how they cope with changing health status in their own terms. In the pilot phase five years ago, many patients had commented on links between their illness and the chemical fallout from the war. Moreover, the study was conducted in such a way that the participant often learned something new about the disease, environmental degradation and/or their personal context in relation to the war.

This participatory approach validates the patient's lived experience and their disease narrative. I pursued these narratives in informal clinical and non-clinical sites as inspired by the muwahaja approach in Islamic legal tradition. ${ }^{13}$ Muwahaja represents the face-to-face mediation and resolution of complaints. Through this approach, my participants encouraged me to revise my own perceptions of Kuwaiti medical knowledge. More specifically, they wished that I address how and by whom medical knowledge is produced, and why the release of this knowledge would be obfuscated following armed conflict. According to the popular press, the Kuwaiti State has been defining disease risk for the public both at the individual and societal levels. ${ }^{14}$

\section{PIECING TOGETHER KUWAITI MEMORIES: NARRATIVE ANALYSIS AND EXPLANATORY MODELS}

Many anthropologists have reached a consensus that the most efficacious methods for healing traumatized individuals involve "talking openly about their pain and suffering”. ${ }^{10,11}$ Indeed, many countries have established Truth and Reconciliation Commissions, which are official bodies that record and synthesize victims' and perpetrators' narratives, in order to encourage a national dialog that unearths traumatic narratives. ${ }^{15}$ These narratives seek to break through the institutional "wall of silence" such that the country will later be able to move forward and reach national reconciliation. ${ }^{15}$ These commissions have brought a sense of community justice to Rwanda, Yugoslavia, Morocco and South Africa, among others, following great societal transformation and trauma. ${ }^{15}$ Yet, such a commission would probably prove to be quite difficult to implement in Kuwait. Again, taking into consideration local issues of honor and family pride, I do not think that many individuals would be willing to come forward to testify about their traumatic experiences. Participant narratives, collected on an individual basis, inform the researcher to better trace the path of illness: When did the illness first present? Was there a life change that provoked these symptoms? Essentially a good clinician knows how to listen and record the medical history and, more importantly, the trajectory of his or her patient. The participant will recount, usually in a piecemeal fashion, the putative causes of illness, and by establishing points of reference between the body, self and society, be able to later reconstitute his or her health that has often been shattered by illness. ${ }^{11,16}$ Moreover, narrative reconstruction engages and exposes the "discursive consciousness". ${ }^{16}$ In some cases, these narrative-based discussions may lead to partial explanatory models.

Interestingly, participant perceptions may include supernatural or social reasonings to explain his or her illness. In Kuwait, many patients have cited "God willed it so," (I am translating from comments wherein Allah was cited for God) or "this (illness) came from above," as rationale 
for their symptoms. Many believed that the best cure was adopting a more pious lifestyle and making the obligatory pilgrimage to Mecca. As Kleinman outlined in his seminal volume on explanatory models, The Illness Narratives, patients often bring their own interpretation of their illness' etiology to the clinic. ${ }^{9}$ Many Kuwaitis, contrary to Americans, will explain that God has willed it such; these patients defer to religion as an explanation for their disease. Indeed, Islam may offer identity, courage, pride, continuity and hope to suffering patients. ${ }^{17,18}$ Like most religions, Islam deems that individuals are more than mind and body, but also spirit and soul. The researcher should thus be prepared to contend with the piety of the patients with whom $\mathrm{s} /$ he relates. In deference to these religious codes, I adopted a courteous manner in my interview style. Any such exchange with informants should encourage a rapport of openness, free of prejudice, while listening to gut impressions and feelings. ${ }^{9}$

A micro-macro mix would include data from both the individual informant in concert with information about the informant's context, normally social and political processes operating to influence broader health care issues. I have sought to employ interviews in my research because my dissertation examines how violence- both lived and secondary - becomes embodied. By "embodied" we mean that the individual has experienced so much violence that it has caused insults to his/her bodies in ways that may not be obvious. ${ }^{19,20}$ In other words, this violence may lead to health consequences in later life.

\section{RECRUITMENT METHODS}

From my most recent Kuwait visit, I gathered participants based on the targeted snowball method (ie, asking others for suggested participants, and, in turn, asking participants for suggestions of other participants, etc.). ${ }^{21}$ The snowball method enabled us to overcome difficulties recruiting Kuwaitis "off the street," where perceptions of a foreign researcher may impede recruitment. Also, discussing the war and its consequences is a slightly sensitive topic - one that many may not want to engage without a proper introduction. The first two participants were recommended to me by colleagues at American University of Kuwait. My colleagues provided either email or phone numbers for these potential participants.

I believe that the best way to understand alienation and collective trauma - my major outcomes- is by examining the lived experience of Kuwaitis, over 95\% of whom were Gulf War survivors. These survivors possess vivid memories about wartime experiences, from which we can extrapolate a more general view on Gulf War trauma, Post-Traumatic Stress Disorder (PTSD), spirituality and chronic disease in the post-conflict period. Therefore, participants must have lived the majority of their lives in Kuwait and must have been familiar with and interested in medical or environmental issues or both. By "familiar with" we are referring to their acquired expertise, either through formal education, their own lived experience or both. By “interested in," we are referring to their demonstrated knowledge, ideas, insights into the connections between increased rates of diseases and chemical and psychosocial exposures (e.g., tor- ture, POWs) from the Gulf War. During the recruitment process, the researcher did not solicit participants' credentials, such that many autodidacts were invited to participate as well.

The environmental health community was defined broadly (i.e., inclusion criteria) as individuals educated and/ or concerned by environmental health, health and toxicological issues in Kuwait since the Gulf War. These individuals included professionals, students, providers, advocates, patients, NGO workers, government officials and employees, academics, and laborers. Many worked in an environmental NGO, while others worked in a hospital or in the government. Patients were able to express their lived experience, having both succumbed to disease and having lived through the war exposures. Additionally, per the IRB's application, they must have been between 18 and 85 years old. This study was approved by the University of Washington's IRB. Also, local ethics review was conducted and approved by Kuwait's Ministry of Health Ethics Review Board. Almost all names were anonymised except for a couple participants who agreed to have their real names used.

As explained above, I practiced active listening techniques. For example, if you ask the patient a question and, rather than answering the question, he or she returns to an earlier question, you, the researcher, should follow his or her train of thought. If the patient wants to avoid scrutiny from his or her family, we proposed to meet at another time or place away from the family. A good researcher is responsive to his or her participants' perceptions and level of participation. Naturally, as I was speaking in the local language (Kuwaiti Arabic), I was very effective in establishing rapport with the participants. As I conducted my research, I spoke in Arabic and English with my participants. For subjects who are not fluent in English, I hired a part-time interpreter to assist me during the survey process (in other words, all transcripts were in English). It was critical to establish linguistic rapport with the respondents as well as with other family members who may also have experienced similar health issues.

Twenty-six Kuwaiti community members, roughly balanced between NGOs, academia, patients and government, were invited to participate in the face-to-face interviews (Table 1). The interviews I conducted lasted between 45 and 90 minutes each, and I conducted each. The interviews were conducted in a mutually agreed-upon location. Before the interview each community member received the list of questions and background information about the project (see Table 2 and consent form in Appendix S1 in Online Supplementary Document). The questions asked about the effects of environmental pollution on health in Kuwait and how related decisions have been made since the war on environmental clean-up. The interviewers audio-recorded the comments made during the interview using an electronic recording device. Later, the researcher transcribed these interviews.

As with any interview guide, the participant sometimes directed the conversation in another direction at his or her will. If answers were not clear, the researcher requested a second interview, the length of which would be at the participant's discretion. As part of the study's IRB approval, no demographic information was collected during these inter- 
Table 1. Types of key informants by sector

\begin{tabular}{lccc}
\hline Sector & Number of individuals & Interest in environmental issues & Interest in health issues \\
\hline NGOs & 6 & 4 & 2 \\
Governmental & 6 & 2 & 4 \\
Private & 4 & 2 & 2 \\
Academic & 6 & 3 & 3 \\
Patient & 4 & 2 & 2 \\
Total & 26 & 13 & 13 \\
\hline
\end{tabular}

NGO - non-governmental organization

Table 2. Interview guide questions

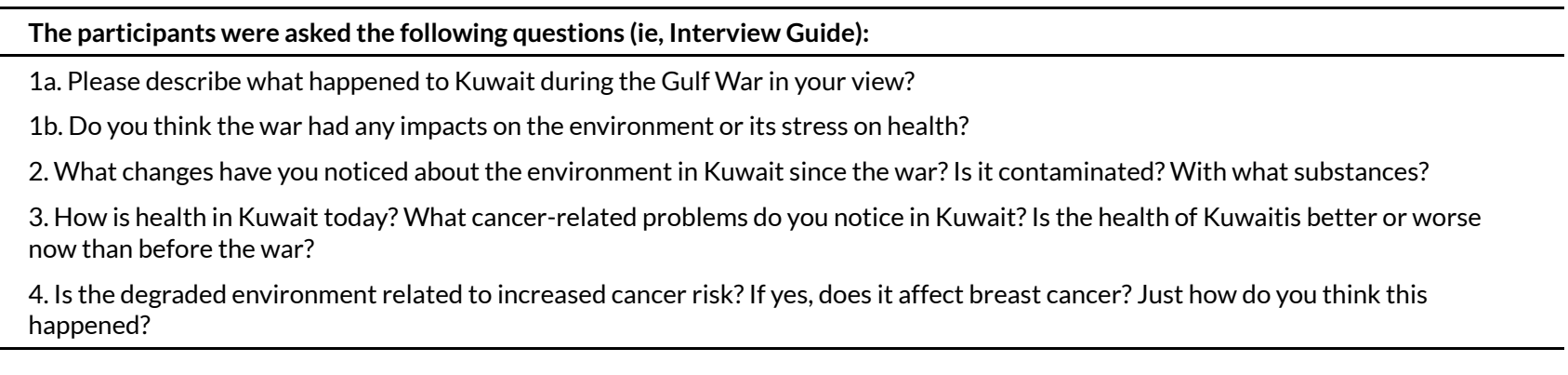

views, and the participants' names were changed to protect their privacy. The interviews were transcribed from the recordings. Then, I analyzed the transcriptions by reading through them several times and identifying by hand the key themes that emerged from the data. With these themes in mind, I collected the relevant quotes for this synthesis.

\section{TRAUMA AS A WESTERN CONCEPT}

In his tome Everything in Its Path, Kai Erikson developed the notion of collective trauma. ${ }^{22}$ Helman notes that individual-level PTSD is a major indicator of collective trauma following violent conflict. ${ }^{15}$ Indeed, other studies have shown that PTSD-affected individuals have higher levels of social alienation and reported lower self-assessed health. ${ }^{23-25}$ In my interviews, I wanted to explore the issues of stress and trauma. I put more emphasis on stress here because in Kuwait "trauma" is not a well-known concept. While mental health practitioners, most of whom have trained in the West, are quite familiar with trauma, there was little to no background knowledge among the participants of what trauma entails and if it has affected a certain segment of Kuwaiti society.

\section{RESULTS}

Everybody's talking about the chemicals, even in the newspaper. Fish wash up on the shore in mass, dead. We've never seen this before in the history of Kuwait, seen things, like diseases, that we were not familiar with before. Hoda, Former Diplomat

\section{COLLECTIVE TRAUMA: VIOLENCE EMBODIED}

Collective trauma was the first of three common themes that concerned many of my interviewees in the post-conflict period. In this theme, interviewees identify a delicate balance between mental and physical health. For cancer patients, in particular, these two states are intrinsically linked. If one feels out of balance because of war-related effects, either physically or mentally, the other state may suffer as well- leading to embodiment. Another factor that leads to individual-level alienation, specifically for Kuwait, is physical vulnerability. ${ }^{26}$ Together, these factors promote self-alienation in Kuwaitis, and summarily influence poorer health-related behaviors (eg, addictions, partner violence). ${ }^{24,27}$ These behaviors may be tied to feelings of social disintegration, stress and trauma that were expressed in several interviews:

The War affected all of us, all who were here. Everyone in Kuwait is marked in some way. - Sara Akbar, Environment Interest

When I first met Wael, the most remarkable thing about him was his stutter. Although he didn't enunciate it, most likely the stutter was a result of the trauma of this one event:

I was on the roof to get water from the tank and all of a sudden, a bullet whizzed by my face. It was two inches from my hitting my nose. My two brothers were taken as POWs. One was eventually returned, the other never did. - Wael, Environment Interest

The other piece to Wael's comment is that the war was very tangible, something palpable in the Kuwaiti existence. Wael comes from an upper-middle-class family, well-educated. The Iraqis were not targeting certain social classes 
or certain groups of individuals. Rather, in a small country, with a small local population, many individuals were affected.

There were many, many horrible things that happened (during the war). The Iraqis used to torture our men for days, weeks even, in secret rooms throughout the country. When they came back, they were messed up forever. Selma, Health Sector

You couldn't go out; the Iraqis were everywhere. Terrorizing people, absolutely, and shooting, and the killing, and raping and stealing everything. I mean brutal terrorism. Suddenly, a bomb went off near the area where I was living. And we ran to the basement and once there, I passed out. I felt something warm coming up my leg and when it reached my heart I passed out completely, and of course, we had gas masks. I thought, 'If I pass out, how am I going to help my children (put on the masks)? I'd better get out.' So, I had my car and headed to the Saudi border. Once we got there, I couldn't pass. They wouldn't let me pass. "Go back!" the guard barked at me with (his) gun in my face.

“Go back!” - Wadha, Health Interest

As noted above, nearly all Kuwaitis were affected by an intense dose of trauma.While some individuals might not have been directly exposed, for example, to torture, or were in some way shielded from its effects, the long-term effects on Kuwaiti health have not been publicly studied. Indeed, the rates of PTSD ( $20 \%$ of Kuwaitis) have stayed the same in Kuwait since 1991, which seems to suggest that many individuals have not recovered from these atrocious events. ${ }^{28}$ Before 1991, less than $10 \%$ of Kuwaitis were affected by PTSD. ${ }^{18}$ As Selma cites in her interview, there is a sense of the Kuwaiti psyche before and after the war. In the before period, there was a relatively good time- people were enjoying new freedoms, many Kuwaitis were traveling abroad to the West for their higher education or for leisure. For many of the Kuwaitis I interviewed, however, the post-war period is a darker time, a more severe time, when a group of individuals was forcibly expelled from the country (i.e., 400,000 Palestinians - while a few thousands stayed, the rest never returned) and new groups of individuals were brought in, and in my everyday discussions with Kuwaitis there was a great amount of suspicion toward these individuals - and, indeed, toward most foreigners in general.

I heard many such stories of despair and horror during my fieldwork in Kuwait. In general, there appears to have been a massive amount of physical and psychological torture that occurred during the occupation. I did not inquire about torture unless the participant was willing to discuss the matter, because it can serve as a unwanted trigger of a psychological response. Perhaps for now, it is most important to reiterate that the amount of suffering and stress was very high, and that in 1991 the average Kuwaiti felt like his or her world was coming to an end. ${ }^{17}$ While it is quite normal to let such events go unspoken at present, the body does not forget. ${ }^{19,29}$ And, indeed, the scars of the trauma may only come to the surface many years later, either as pathological behavior or as a physical outcome. ${ }^{10,29}$

These trauma- and stress-related quotes demonstrate a sensitivity to the embodied being with a particular life meaning. ${ }^{30}$ Capturing life meaning integrates political, economic and historical approaches by examining structural, contextual factors as they pertain to health outcomes. ${ }^{31,32}$ For many Westerners, with the obvious exception of deployed soldiers, it would be difficult to conceptualize the Gulf War experience, as we have not lived through such an event. As Wael and Sara pointed out in their testimonies, the mind became another battlefield of the war, especially at a time when individuals often felt out of control of their own circumstances and, indeed, of their own bodies. 33,34 Perhaps it is this fatalistic tendency, combined with a unrelenting sense of collective trauma that has become entrenched in the country's consciousness. These dual issues have likely played a role in wreaking havoc on Kuwaiti health.

\section{A TOXIC LEGACY: WAR AND CHEMICAL EXPOSURES}

During the Gulf War, there was no doubt that Kuwait sustained irreparable damage as a result of the massive oil well fires that plagued the country for nine months. Also, the US deployed depleted uranium munitions as a fail-proof antitank measure during the war. Here I will cite some portions of the interviews (see Table 2) that focused on the notion of Gulf War pollution and disease etiology:

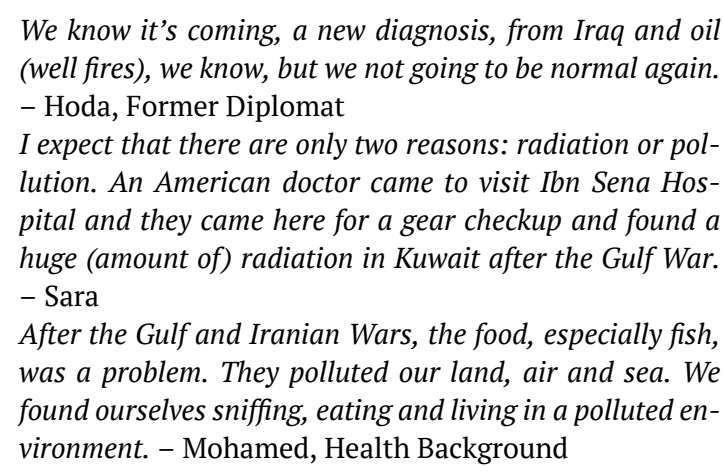

Sara cites the "American" source because this lends legitimacy to her claim. Others cite the environment at largefor example, the fish. Indeed, in many of my interviews, individuals mentioned how the environment had gotten much worse since the war period. The 2001 "fish kill," although ten years after the war ceased, represents, at the least, a symbol of the continuing contamination and delayed clean-up, and the general lack of vision that pervades Kuwaiti concern for the environment.

Moreover, Hoda cites pollution as a major cause of the rise of allergies and asthma, before honing in its role in carcinogenesis:

Everybody has asthma these days, like my neighbors and my son. Other people have allergies and itching skin. It's so polluted, that what happened in 1991 and now, I'm $100 \%$ sure that it affects us: bombing, dead bodies, the chemicals absorbed in the soil. Some people are not talking about (cancer), but it's running like a flu now. What's going on in Basra [Birth defects and childhood leukemias have risen between $200-400 \%$ in the Basra region since 1997], "it's here. I mean, we're only one hour from Iraq, you know. It's in our surroundings. ${ }^{*}$ Hoda, idem

In these testimonials, each individual has evoked a change in disease rates that he or she feels is, at least par- 
tially, related to the war. "It's running like a flu now" or "Every family has a case of cancer- which we didn't see before the war" is a common refrain I heard from my Kuwaiti participants. Patients present in clinic with cancer symptoms at a much higher rate in the post-conflict period. Moreover, these are educated individuals, so it is unlikely that they were not aware of screening or public health interventions before the war:

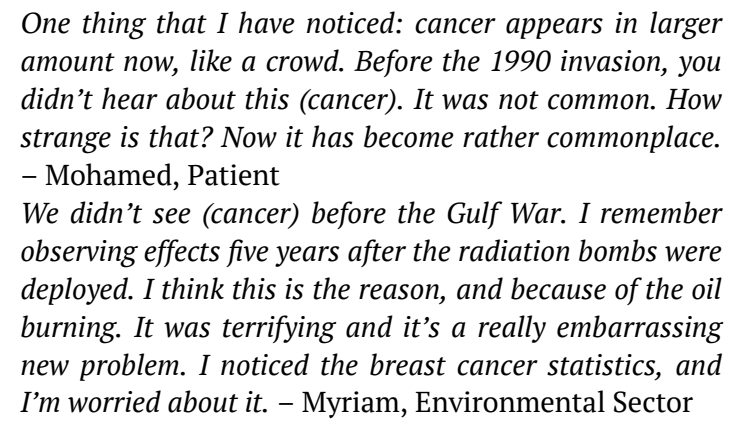

One thing that I have noticed: cancer appears in larger amount now, like a crowd. Before the 1990 invasion, you didn't hear about this (cancer). It was not common. How strange is that? Now it has become rather commonplace. - Mohamed, Patient

We didn't see (cancer) before the Gulf War. I remember observing effects five years after the radiation bombs were deployed. I think this is the reason, and because of the oil burning. It was terrifying and it's a really embarrassing new problem. I noticed the breast cancer statistics, and I'm worried about it. - Myriam, Environmental Sector

The main issues revealed in this section have exposed a heightened sense of awareness of environmental contamination, a clear change in rates of cancer rates pre- and postwar and, lastly, the variable nature of official statistics. Indeed, for Sara, Mohamed and Myriam, there was a general sense of the pervasiveness of the wartime toxins and how they most likely had long-term impacts on individual health. The images of the oil fires were etched into the collective memory, and, moreover, they serve as the quintessential symbol of the Gulf War. At a certain level, if the local population had noticed an increase in disease, then this observation becomes empirical evidence and should be officially taken into account. As several of my interlocuters mentioned, there is a general belief that the official government statistics have been manipulated. After all, the State has a strong interest not to divulge an abnormal increase in cases that may open the door to claims for compensation. ${ }^{14,34}$ Unlike Chernobyl and Russia, the Kuwait State has very deep coffers and a populace that is well aware of its legal rights and recourses under Kuwait law.

\section{WHOSE CLINIC IS IT? DEFINING RISK WHEN THE RISKS ARE INVISIBLE}

How diseases are measured and recorded depends largely on the patient's contact with his or her doctor. In the clinic, doctors observe most readily the patient's symptoms while trying to hypothesize on the origin of the disease. ${ }^{8,15}$ In post-conflict societies, however, this origin is often elusive and/or multifaceted. ${ }^{9,19}$ Clearly, there is a dependence on, but also great skepticism of, the Kuwaiti health care apparatus. In Kuwait, many of my informants cited issues around the lack of transparency or perceived neglect on behalf of the government to effectively pursue, track and document the increase of various diseases:

Three of my close friends have hyperthyroidism. I don't think the Ministry of Health wants to look into it- it might be suppressed. It's for political reasons. It (should be) about prevention- there's a screening test for breast cancer, really caring for it.

We need to document (the diseases). It is restrictive in the hospitals here. The associations (disease-environment) are a good place to start. We need your help. It's going to be used. - Hoda, idem

Now a lot of the people are dying from cancer, but we didn't find out until it was too late...We smell the same air. They shouldn't be denying it, they should just leave, then do more screening for breast cancer. - Dr. Iqstal, retired Kuwaiti pediatrician

In the end, it's all caused by politics. - Hoda, idem

These individuals highlight a certain amount of disdain, if not contempt, for the health care system and the decision-makers in charge of it. For example, the first informant uses the word "suppressed." The last quote in particular implies that the system has been abused by external political forces. Many cancer patients wish that the Ministry of Health would take a more active role in screening, tracking and researching links to chemical exposures.

Why are we seeing the same illnesses in Gulf War veterans
in your country? - Dr. Iqstal, retired Kuwaiti pediatri-
cian

One chemical in particular that has been at the brunt of claims of contamination and exposure in post-conflict Kuwait: Depleted Uranium, also known as “DU.” Many individuals have commented to me about this noxious chemical and believe that it has clear and devastating effects on human health- namely causing cancer and birth defects:
The thyroid problems from depleted uranium are really a high number. - Hoda
They've (Iraqis) thrown bombs here and there, all over Kuwait, this small land. It's enough to cover a continent. Eventually they brought in companies for cleanup, burning oil and dumping oil in the sea. - Talal, Health Interest The uranium (debris) is going to stay. It's not going to move unless you do something about it. A special on Al- Jazeera noted that the (uranium) dust has been detected in Europe after the sandstorms in 2004. - Talal, idem

However, many Western scientists have often minimized their claims regarding depleted uranium (DU), both in public and in private, leading Kuwaitis, as they themselves highlight above, to believe that Westerners do not take this issue seriously. Morever, radiation is an invisible substance - one cannot contain, smell or feel it. So, residents often wonder how they know if it is there. Can it dissipate? How? When? I breached the emerging concern of DU exposures in an earlier paper on the effects of the Gulf War. ${ }^{35}$

Certain risks, such as physical ones, are considered more measurable and, in a biomedical sense, more valuable than mental health risks in many post-conflict societies. ${ }^{10,36}$ And, as implied in the data, the politics of wartime exposures ends up playing a substantial role in defining these risks for Kuwaitis. While there was one clinic established expressly for the sole purpose of treating mental health conditions (Al-Riggae), the clinic was closed in 2001. In most clinics, the doctor is the sole official who can determine- or at least authorize- the most efficacious course of treatment. ${ }^{8,37}$ The quotes above demonstrate a certain distrust and disbelief in the State narrative vis-à-vis environmental and health issues. In particular, they draw links between the events of the Gulf War - notably the oil well 
fires- and persistent environmental and health problems in Kuwait.

\section{DISCUSSION}

This article has developed three themes that informants identified in their own experiences with rising disease rates in contemporary Kuwait: "Violence Embodied," "A Toxic Legacy" and "Defining Risks." By giving these informants an active voice in the research process, I have been able to examine how the Kuwaiti environmental and public health community perceives the role of the Gulf War and the environment. Many informants expressed concern that environmental contaminants are playing a role in the rising prevalence of diseases such as breast cancer. There were only a couple hundred cases of breast cancer recorded per year before 1990. Given the sophisticated nature of Kuwait's health care system before the war, this documented increase was not likely due to a lack of screening or reporting - as several Western health professionals have intimated to me in various briefings in the US. Post-war, however, my informants described a political climate in the Ministry of Health that fostered a lack of transparency and trustworthiness related to the war's toxic legacy as the third-worst environmental disaster in history. Such a reckoning, however, would damage the war's universally accepted narrative as a "quick, clean intervention.”

As Nikolas Rose reminds us, NIH-funded researchers are mandated to divulge their findings in open-source publications. ${ }^{38}$ Thus, the US government is ethically compelled to confirm that its own research has demonstrated its former Gulf War-era soldiers may suffer from weapons-related toxic exposures. ${ }^{39,40}$

Ongoing exposure to war-related toxins creates a health risk for Kuwaiti civilians today and, indeed, for an indeterminate period of time in the future. This reality raises several important questions:

1. Why is the American public and government not paying more attention to the cleanup of this man-made disaster?

2. Who is ultimately responsible for the remediation of war-related toxins?

3. How effective is the UN agency (ie, UNCC) established for Gulf War-related remediation and compensation in fulfilling its responsibilites?

4. How is it that the third-worst man-made environmental disaster (after Chernobyl and Bophal) receives so little international attention?

It is quite clear that all Kuwaitis continue to be affected by the war and that the collective trauma in Kuwait was unparalleled. ${ }^{41}$ One wonders about the cumulative impact of the psychological stress from the war and how this relates to overall morbidity among Kuwaitis.

Upwards of $90 \%$ of Kuwaitis were exposed to some level of highly toxic petrochemicals, soot and trace amounts of depleted uranium from war munitions. ${ }^{36}$ Furthermore, environmental exposures incurred during conflict become both physically and psychologically embodied and build slowly over time inside the individual. Sara, Myriam, Wadha, Wael - many of my participants echoed these sentiments in their comments to me in this study.

As a result, these individuals may be much more susceptible to carcinogenesis, neurological damage or other physical and psychological impairments than non-exposed peers. ${ }^{8}$ For example, tortured Kuwaiti POWs, as Wadha mentioned in our interview, suffered both severe physical and mental wounds. ${ }^{42}$

Further research has suggested that disease etiology is highly influenced by the accumulation of stress from torture or witnessing acts of torture. ${ }^{15,22}$ And while the effects of depleted uranium remain contested, as Talal and other participants noted earlier, the vast amount of carcinogenic petrochemicals recorded in the water, food chain and the environment at large means that these chemicals will persist in the environment to destroy Kuwaiti health for generations to come.

\section{ACKNOWLEDGEMENTS}

The author would like to express appreciation to his advisor James Pfeiffer for providing feedback on earlier drafts. Also, Sarah Chard and John Holmes provided helpful feedback on later drafts.

\section{FUNDING}

The author would like to recognize the US Fulbright Scholarship Board for awarding him both a student Fulbright award and a Fulbright-Hays dissertation award to be able to conduct this work in Kuwait. This work was also supported by three US Department of Education Foreign Language Area Studies (FLAS) awards. Lastly, this work was partially supported by two University of Washington graduate student travel awards.

\section{COMPETING INTERESTS}

The author has completed the Unified Competing Interest form at http://www.icmje.org/coi disclosure.pdf (available on request from the corresponding author) and declares no conflict of interest.

\section{CORRESPONDENCE TO}

Charles Cange, $\mathrm{PhD}$, MSc

250 Bedford Park Blvd W, Office 422

Bronx, NY 10468

United States of America

cange@uw.edu 


\section{REFERENCES}

1. Jick TD. Mixing qualitative and quantitative methods: triangulation in action. Adm Sci Q. 1979;24(4):602-11 \. doi:10.2307/2392366

2. Sandelowski M. Combining qualitative and quantitative sampling, data collection, and analysis techniques in mixed-method studies. Res Nurs Health. 2000;23:246-255. doi:10.1002/

1098-240X(200006)23:3<246::AID-NUR9>3.0.CO;2-H

3. Abu-Lughod L. Writing Women's Worlds: Bedouin Stories. University of California Press; 2008.

4. Eytan A, Gex-Fabry M, Toscani L, Deroo L, Loutan L, Bovier PA. Determinants of postconflict symptoms in Albanian Kosovars. J Nerv Ment Dis.

2004;192(10):664-671. doi:10.1097/01.nmd.00001420 $\underline{29.96703 .57}$

5. Pham P. Lazarus rising: civil society and Sierra Leone's return from the grave. Intl J of Not-for-Profit Law. 2004;7:49-76.

6. Harvard School of Public Health. Harvard Scientists Report Public Health Impact of 1990 Iraq Invasion of Kuwait: Higher Rates of Mortality Evident Among Kuwaiti Civilians Who Remained in Kuwait During Occupation. Published June 29, 2005. Accessed August 28, 2005. http://www.hsph.harvard.edu/news/ press-releases/archives/2005-releases/press0629200 $\underline{5 . h t m l}$

7. Barbosa CS. Epidemiology and anthropology: an integrated approach dealing with bio-socio-cultural aspects as strategy for the control of endemic diseases. Mem Inst Oswaldo Cruz. 1998;93(suppl 1):59-62. doi:10.1590/s0074-02761998000700008

8. DiGiacomo SM. Can there be a "cultural epidemiology”? Med Anthropol Q. 1999;13(4):436-457. doi:10.1525/maq.1999.13.4.436

9. Kleinman A. The Illness Narratives: Suffering, Healing, and the Human Condition. Basic Books; 1988.

10. Abramowitz SA. The poor have become rich, and the rich have become poor: collective trauma in the Guinean Languette. Soc Sci Med.

2005;61(10):2106-2118. doi:10.1016/j.socscimed.200 $\underline{5.03 .023}$

11. Henry D. Violence and the body: Somatic expressions of trauma and vulnerability during war. Med Anthropol Q. 2006;20(3):379-398. doi:10.1525/m aq.2006.20.3.379
12. Bernard HR, Ryan G. Analyzing Qualitative Data: Systematic Approaches. SAGE Publications; 2009.

13. Brinkley M. The Calligraphic State. Textual Domination and History in a Muslim Society. University of California Press; 1993.

14. Cancer: the tide to come. The Kuwait Times. 2009.

15. Helman C. Culture, Health and Illness. CRC Press $\underline{\mathrm{d}}$ oi:10.1201/b13281

16. Williams G. The genesis of chronic illness: narrative re-construction. Sociol Health Illn. 1984;6(2):175-200. doi:10.1111/1467-9566.ep1077825 $\underline{0}$

17. Al-Mounir J. Personal Interview; 2008.

18. Report on the Psychiatric Effects of the Iraqi Aggression. Ministry of Health/State of Kuwait; 1995.

19. Scheper-Hughes N. Death without Weeping: The Violence of Everyday Life in Brazil. University of California Press; 1992.

20. Krieger N. Sticky webs, hungry spiders, buzzing flies, and fractal metaphors: on the misleading juxtaposition of "risk factor" versus "social" epidemiology. J Epidemiol Community Health. 1999;53(11):678-680. doi:10.1136/jech.53.11.678

21. Mason C. Maternal and child health needs in Northern Ireland and Jamaica: official and lay perspectives. Qual Health Res. 1994;4(1):74-93. doi:1 $\underline{0.1177 / 104973239400400106}$

22. Erikson KT. Everything in Its Path. Simon and Schuster; 1976.

23. Ginzburg K, Solomon Z, Dekel R, Neria Y. Battlefield functioning and chronic PTSD: associations with perceived self efficacy and causal attribution. Pers Individ Dif. 2003;34(3):463-476. doi:1 0.1016/s0191-8869(02)00066-1

24. Adams RE, Boscarino J. Stress and well-being in the aftermath of the World Trade Center attack: The continuing effects of a communitywide disaster. $J$ Community Psychol. 2005;33:175-190. doi:10.1002/jco p.20030

25. Salick EC, Auerbach CF. From devastation to integration: Adjusting to and growing from medical trauma. Qual Health Res. 2006;16(8):1021-1037. doi:1 $0.1177 / 1049732306292166$ 
26. Pepin-Wakefield Y. The use of projective drawings to determine visual themes in young Kuwaiti women impacted by the Iraqi invasion. Int J Art Des Educ. 2008;27(1):70-82. doi:10.1111/j.1476-8070.2008.0055 9.x

27. Ministry of Information. State of Kuwait. Kuwait Health; 2006.

28. Hammadi A. Examining PTSD in the Kuwaiti Population after the Iraq War.2005.

29. Chirot D. Contentious Identities: Ethnic, Religious and National Conflicts in Today's World. Routledge; 2012. doi:10.4324/9780203834190

30. van Manen M. Modalities of body experience in illness and health. Qual Health Res. 1998;8(1):7-24. d oi:10.1177/104973239800800102

31. Morsy S. Political economy in medical anthropology. In: Medical Anthropology: A Handbook of Theory and Method. Greenwood Press; 1990:26-46.

32. Baer R. Health and mental health among Mexican American migrants: Implications for survey research. Hum Organ. 1996;55(1):58-66. doi:10.17730/humo.5 5.1.y30712lp869g6047

33. Nordstrom C, Robben A. Fieldwork Under Fire: Contemporary Studies of Violence and Culture. University of California Press; 1996. doi:10.1525/calif ornia/9780520089938.001.0001

34. Petryna A. Life Exposed: Biological Citizens after Chernobyl. Princeton University Press; 2002.
35. Cange CW. The life course model as a framework for post-conflict health analysis: reflections on the Gulf War critical period. Med Confl Surviv. 2016;32(4):282-294. doi:10.1080/13623699.2016.1269 $\underline{284}$

36. Bloom S. Hidden Casualties: Environmental, Health and Political Consequences of the Persian Gulf War. ARC/Arms Control Research Center; 1994.

37. Foucault M. The Birth of the Clinic. Tavistock; 1973.

38. Rose N. The Politics of Life Itself: Biomedicine, Power, and Subjectivity in the Twenty-First Century. Princeton University Press; 2007. doi:10.1515/978140 $\underline{0827503}$

39. Roberts B. Export controls and biological weapons: new roles, new challenges. Crit Rev Microbiol. 1998;24(3):235-254. doi:10.1080/10408419 $\underline{891294244}$

40. Baron J. Against Bioethics. MIT Press; 2006.

41. Al-Adwani A. Personal interview. Published online 2011.

42. Casey C, Dinkha J. Memory and Subjectivity among Kuwaiti Youths: Child Witnesses of the 1990 Iraqi Invasion of Kuwait. In: The Second Middle East and North Africa Regional Conference of Psychology. ; 2007. 